\title{
Caracterização de Linhagens Puras Selecionadas de Guandu (Cajanus cajan (L.) Millsp) ${ }^{(1)}$ \\ Rodolfo Godoy1 ,2, Luiz Alberto Rocha Batista ${ }^{2,3}$, Francisco H. Dübbern de Souza², Ana Cândi- da Primavesi ${ }^{2}$
}

\begin{abstract}
RESUMO - O objetivo do presente trabalho foi caracterizar morfologicamente dezessete linhagens de guandu que haviam sido selecionadas por diversos critérios, em ensaios de avaliação agronômica, após o que haviam passado por processos de autofecundação, seleção e multiplicação, para obtenção de linhagens puras. Teve por objetivos também verificar a eficiência dos descritores utilizados e descrever seu ciclo vegetativo. Foi possível fazer essa descrição e concluir que as dezessete linhagens utilizadas possuíam características distintas, pelas quais podem ser facilmente identificadas. Verificou-se que os descritores utilizados revelaram-se suficientes para caracterizar as dezessete linhagens e que podem ser feitas simplificações nos descritores. As sementes das cultivares comerciais utilizadas no presente trabalho possuíam mistura mecânica.
\end{abstract}

Palavras-chave: descrição botânica, avaliação, forrageira tropical

\section{Description of Selected Pigeon-pea (Cajanus cajan (L.) Millsp) Pure Lines}

\begin{abstract}
The purpose of this work was to characterize morphologically seventeen previously selected pigeon-pea lines that went, after selection, through processes of self pollination, selection and multiplication, to obtain pure lines. It also had the objectives of checking the efficiency of the descriptors and describing its vegetative cycle. It was possible to perform the description and to conclude that the seventeen lines have distinct characteristics and can easily be identified by these traits. The used descriptors could properly perform this task and it was concluded that they can be simplified. The seeds of the commercial lines used in this work had mechanical mixture.
\end{abstract}

Key Words: botanical description, evaluation, tropical forage

\section{Introdução}

Grande parte dos sistemas de produção de carne e de leite do Brasil está instalada em áreas de cerrado, caracterizadas por solos de baixa fertilidade natural e longo período de estiagem. Uma das principais estratégias para aumento da eficiência produtiva desses sistemas é a utilização de plantas forrageiras adaptadas à tais condições, dentre as quais destaca-se o guandu. O guandu vem sendo utilizado em diversas regiões brasileiras para diversos propósitos, mais freqüentemente, porém, na alimentação animal, tanto como pastagem exclusiva ou consorciada, como também, na forma de forragem verde, feno e componente de mistura de silagem (Werner, 1979; Wutke, 1987).

Vários estudos conduzidos para caracterizar genótipos de guandu e fornecer informações básicas para o trabalho de melhoramento genético (Werner, 1979; Wutke, 1987; Colombo, 1989), evidenciaram a extraordinária variabilidade genética desta espécie. Considerando as limitações de qualidade e o limitado número de cultivares comerciais de guandu (Godoy et al., 1994, e Godoy et al., 1997), avaliaram agronomicamente duas coleções de germoplasma de guandu e verificaram que todos os acessos apresentavam, em graus variáveis, misturas mecânicas e segregação fenotípica. Por esse motivo, os acessos selecionados tiveram que passar por processos de autofecundação e seleção, para obtenção de linhagens puras. Dezessete dessas linhagens puras apresentavam, em 1998, quantidade suficiente de sementes para a instalação de novos ensaios de campo e vêm, desde então, sendo reavaliadas agronomicamente, para confirmação dessas suas qualidades.

O objetivo do presente trabalho foi caracterizar morfologicamente as linhagens puras selecionadas, descrever seu ciclo vegetativo e verificar a eficiência dos descritores utilizados.

\footnotetext{
${ }^{1}$ Pesquisador(es) da Embrapa Pecuária Sudeste - CP 339 - 13500-970 - São Carlos, SP. E.mail: godoy@cppse.embrapa.br, lbatista@cppse.embrapa.br, fsouza@cppse.embrapa.br, anacan@cppse.embrapa.br.

2 Bolsistas do CNPq.
} 


\section{Material e Métodos}

A caracterização das linhagens puras e descrição de seu ciclo vegetativo foi feita em um bloco de ensaio de avaliação agronômica instalado na Embrapa Pecuária Sudeste, em São Carlos, SP, em 31 de dezembro de 1998, com vinte tratamentos, dezessete linhagens puras e três testemunhas, as cultivares comerciais Caqui, Anão e Fava Larga. As parcelas desse bloco foram constituídas por cinco linhas de 5 $\mathrm{m}$ de comprimento, com espaçamento entre linhas de $0,5 \mathrm{~m}$ e entre plantas de $0,25 \mathrm{~m}$.

Os descritores utilizados, adaptados de International Board for Plant Genetic Resources (IBPGR) e International Crop Research Institute for the Semi Arid Tropics (ICRISAT) (1993), foram: hábito de crescimento, altura de plantas $(\mathrm{cm}) \mathrm{com}$ $50 \%$ das plantas em florescimento, número de ramos primários, número de ramos secundários, espessura do caule $(\mathrm{cm})$, forma do folíolo, pilosidade do folíolo, cor básica (cor principal das pétalas) e cor secundária da flor, padrão das estrias da flor, padrão de florescimento, cor da vagem verde, forma e pilosidade da vagem, cor da vagem madura, padrão de coloração das sementes, cores básica e secundária das sementes, cor ao redor do hilo das sementes, largura do hilo, forma das sementes. Na descrição das cores, foram obedecidos os padrões do British Colour Council (1938), exceto para cores das vagens. O padrão das estrias das flores foi descrito de acordo com o mostrado na Figura 1, o padrão de coloração das sementes, segundo a Figura 2 e a forma das sementes,
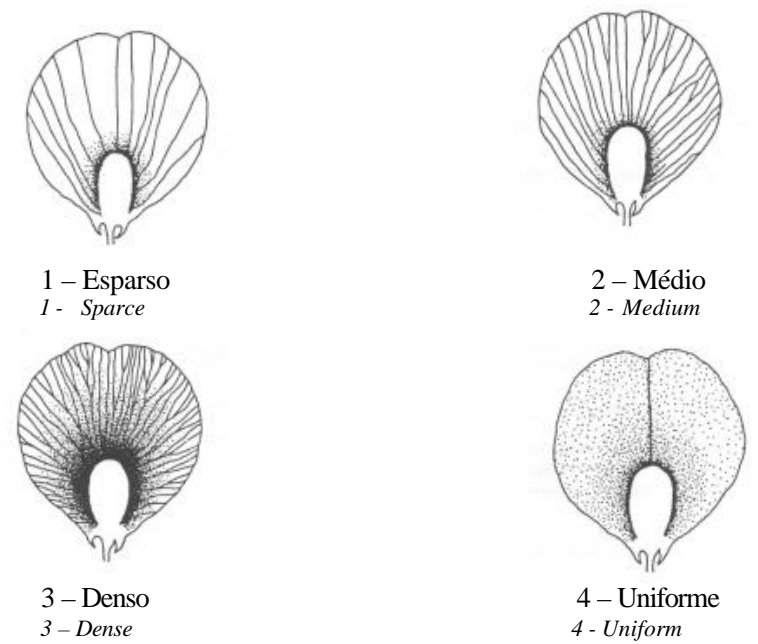

Figura 1 - Padrão das estrias: esparso, médio, denso ou uniforme.

Figure 1 - Patters of streaks: sparce, medium, dense or uniform coverage.

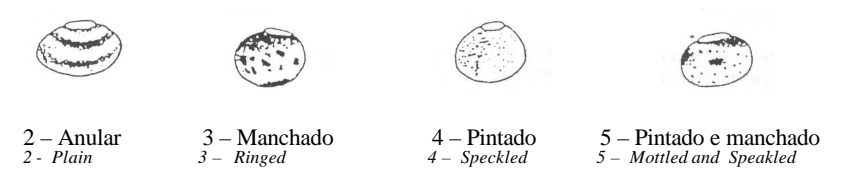

Figura 2 - Padrão de coloração das sementes: liso, anular, manchado, pintado ou pintado e manchado.

Figure 2 - Seed color pattern:plain, ringed, mottled, speckled, mottled and speckled.
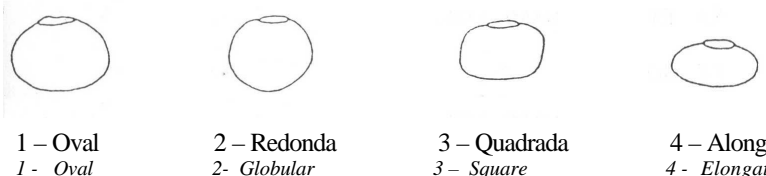

I- Oval

2- Redonda

3- Quadrada

4-Alongada 4- Elongate

Figura 3 - Forma das sementes: oval, redonda, quadrada ou alongada.

Figure 3 - Seed shape: oval, globular, square or elongate.

conforme a Figura 3. Todas essas características foram adaptadas de IBPGR \& ICRISAT (1993).

Para a caracterização do ciclo vegetativo dos genótipos, foi feita simplificação da metodologia recomendada por IBPGR \& ICRISAT (1993), tendo sido utilizados os seguintes parâmetros: dias da emergência ao início do florescimento, até $50 \%$ das plantas estarem em florescimento, até $100 \%$ plantas em florescimento, ao aparecimento das primeiras vagens e até $75 \%$ das vagens estarem maduras. Foi também anotado, em dias, o período de florescimento. De modo geral, procurou-se utilizar apenas descritores que pudessem servir para a caracterização de genótipos de guandu, evitando-se aqueles mais influenciados pelo meio ambiente. Assim, alguns dos descritores recomendados por IBPGR e ICRISAT (1993) não foram utilizados, tais como, número de plantas avaliadas, área foliar, vigor aos $50 \%$ de florescimento, distância entre as vagens mais altas e mais baixas, peso de 100 sementes. Outros não foram utilizados por não terem sido encontrados, como o caso de ramos terciários, ou por não ser possível sua utilização, como no caso das cores, onde a publicação recomendada por IBPGR e ICRISAT (1993) não estava disponível, sendo substituída por BCC (1938), ou descrição simplificada de cores. 


\section{Resultados e Discussão}

Nas Tabelas 1 a 4, observam-se os resultados da caracterização botânica das dezessete linhagens puras e das três cultivares. Verifica-se que duas das cultivares, Caqui e Fava Larga, apresentam plantas com características diferentes entre si, possivelmente devido à contaminação mecânica. IBPGR e ICRISAT (1993) classificaram quatro possíveis hábitos de crescimento: ereto e compacto, semiprostrado, prostrado e rasteiro. No presente trabalho, foram encontrados apenas dois tipos de hábito de crescimento, tendo-se considerado eretos os genótipos cujos ramos primários faziam ângulo menor que $60^{\circ}$ com o caule e semiprostados aqueles cujos ângulos estavam entre 60 e $90^{\circ}$. As cores do caule, da flor, da semente e da região em volta do hilo da semente, mencionadas foram aquelas encontradas quando as plantas foram confrontadas com as cores encontradas em BCC (1938). As vagens verdes foram classificadas como marrom, púrpura escura com estrias verdes, púrpura com manchas verdes, verde, verde clara, verde muito clara, verde escura, verde com estrias púrpuras claras, verde com estrias violetas escuras, verde com estrias violetas escuras na linha de sutura e entre os grãos, verde com manchas violetas escuras, verde com manchas violetas na linha de sutura e entre os grãos, verde escura com estrias violetas escuras, enquanto foram encontradas vagens maduras das cores marrom claro, marrom com estrias violeta, palha, palha com estrias marrom violeta, palha com estrias púrpura, palha com estrias violeta, palha com estrias violeta escuro, palha com manchas escuras junto à linha de sutura e pequenas manchas violeta, palha com manchas escuras na linha de sutura e entre os grãos, palha ocre e violeta escuro. A seguir, são descritas as características encontradas nesta coleção.

Hábito de crescimento: duas linhagens, g17c-94 e g29b-94 possuem hábito de crescimento semiprostrado, enquanto que as demais quinze linhagens e as três cultivares possuem hábito de crescimento ereto.

Altura de plantas: foi encontrada uma linhagem (g58-95) com $65 \mathrm{~cm}$ de altura, uma com $90 \mathrm{~cm}$, g12797, duas entre 100 e $120 \mathrm{~cm}$, Anão e g17-94, seis entre 150 e 170 cm, Caqui, Fava Larga, g6-95, g18-95, g19b-94 e g47-94, e dez entre 180 e $195 \mathrm{~cm}$, g3-94, g27-94, g29b-94, g66-95, g101-97, g124-95, g146-97, g154-95, g167-97e g184-97.

Número de ramos primários: uma linhagem, g-
58-95 apresentou em média, sete ramos primários, uma, g101-97, nove, dez linhagens tinham dez a doze, Caqui, g3-94, g6-95, g17c-94, g18-95, g27-94, g29b94, g47-94, g66-95 e g127-97, seis, quatorze a dezessete ramos primários, Anão, Fava Larga, g12495, g146-97, g154-95 e g19b-94; g184-97 tinha dezenove e g 167-97, vinte e um.

Número de ramos secundários: nove linhagens não apresentaram ramos secundários: Anão, Caqui, g17c-94, g18-95, g27-94, g47-94, g124-95, g127-97 e g154-95; g6-95, g66-95 e g167-97 apresentaram raros ramos secundários. Seis tinham dois, em média, Fava Larga, g3-94, g19b-94, g58-95, g101-97 e g146-97. Duas linhagens tinham três ramos secundários: g29b-94 e g184-97.

Cor do caule: duas linhagens, g124-95e g154-95 possuem caule púrpura lilás $031 / 1$ e verde alface 861/2; g167-97, púrpura amor perfeito 928/1 e verde salgueiro ooo862/1, g 17c-94, verde alface 861 e Anão, verde alface 861 . Três linhagens têm caule verde alface 861 e púrpura lilás o31/1: g3-94, g66-95 e g101-97; g 58-95, verde espinafre o960/1; g27-94, verde lavanda ooo761/1; g18-95 e g6-95, verde salgueiro ooo862 e verde salgueiro ooo862/1, respectivamente; g184-97 e Fava Larga, verde salgueiro ooo862/1 e vermelho sangue de boi oo823/2, porém o último em plantas separadas; g47-94, verde samambaia o862/2 e púrpura cravo 730; g19b-94, g29b-94 eg14697, vermelho sangue de boi oo823 e verde salgueiro oo862/1; g127-97, apenas vermelho sangue de boi oo823 e, Caqui, vermelho sangue de boi oo823 e verde salgueiro ooo862/1, porém em plantas separadas.

Espessura do caule: nenhum dos genótipos apresentou caule fino (menor que $5 \mathrm{~mm}$ ). Dezesseis apresentaram caules considerados por IBPGR e ICRISAT (1993) intermediários (5 a 13 mm), listados em ordem crescente de espessura: g58-95, g127-97, Anão, g18-95, g66-95, g154-95, g167-97, g6-95, g4794, g124-95, g17c-94, g184-97, g3-94, g101-97, g2794 e g29b-94. Caqui, g146-97, g19b-94 e Fava Larga apresentaram caules grossos.

Forma do folíolo: a maior parte dos materiais, Anão, g6-95, g27-94, g47-94, g58-95, g101-97, g124-95, g12797, g146-97, g154-95, g167-97 e g184-97, têm o folíolo em forma elíptica estreita. Caqui, Fava Larga, g3-94, g19b-94 e g66-95, apresentam folíolos com forma elíptica larga e g17c-94, g18-95 eg29b-94, lanceolada. Todas as linhagens possuem folíolos pubescentes.

Cor básica da flor: as três cultivares e quatorze linhagens (g3-94, g18-95, g17c-94, g27-94, g29b-94, 


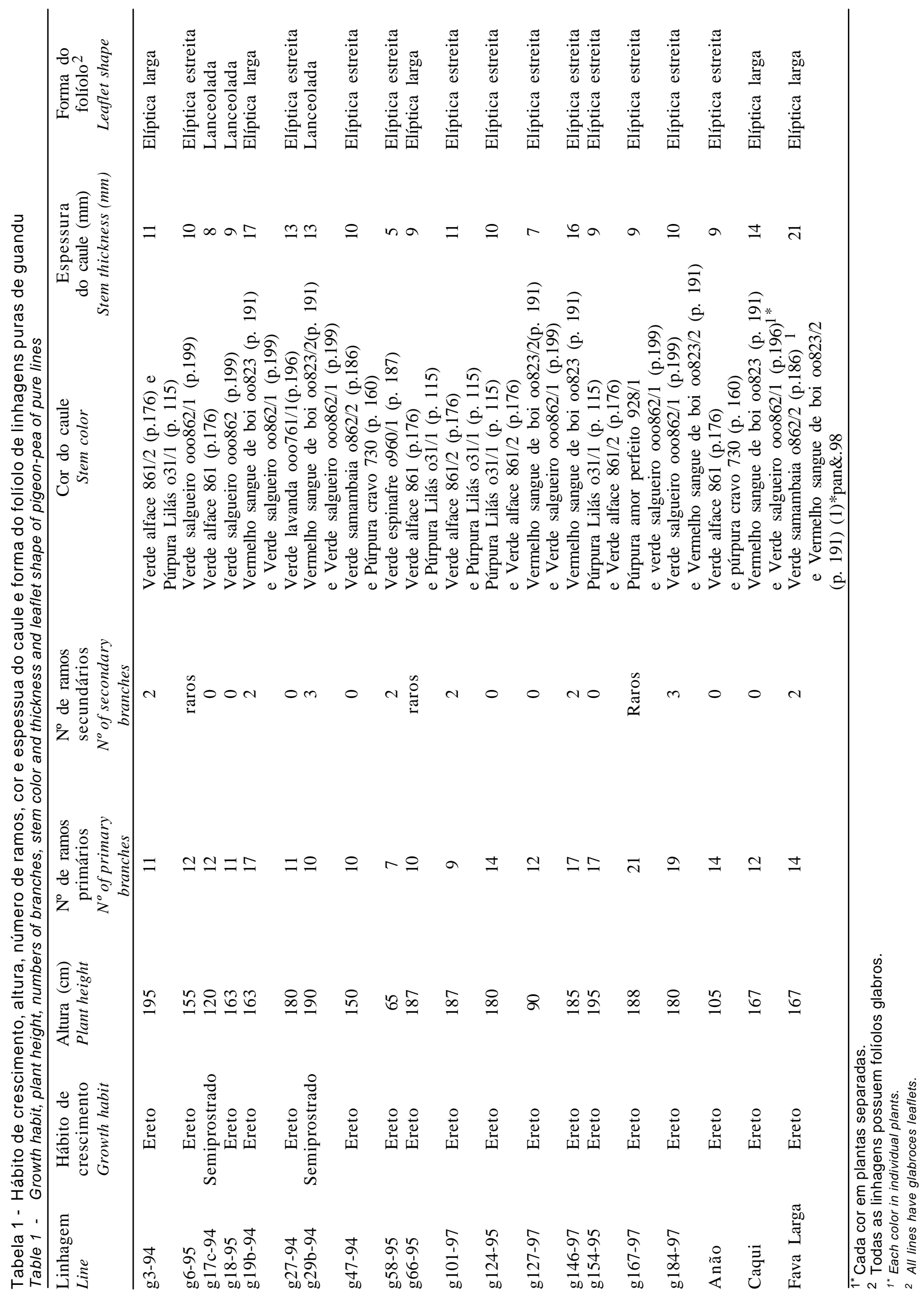




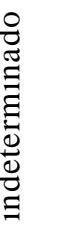

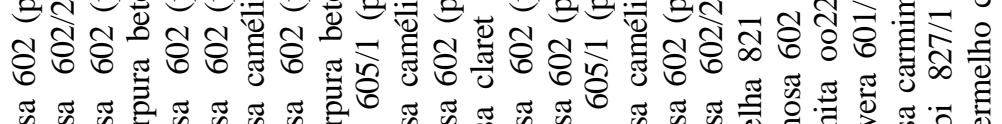
ॠ

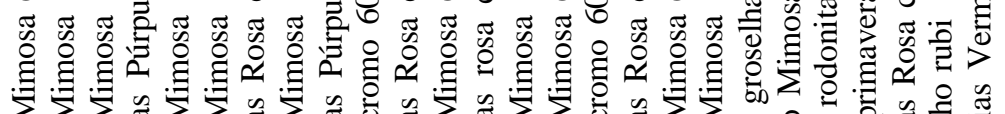

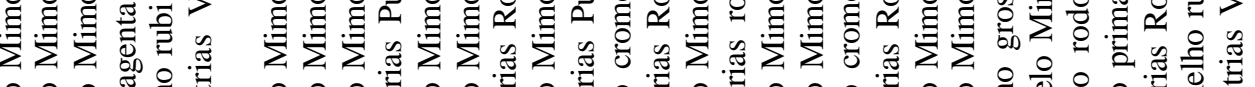

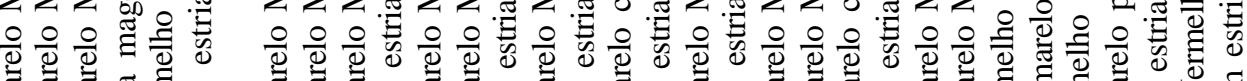

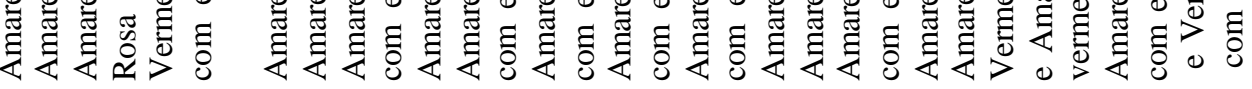


g47-94, g58-95, g66-95, g101-97, g124-95, g146-97, g154-95, g167-97 e g184-97) têm o amarelo cromo 605/1 como cor básica da flor. Amarelo cromo 605 com mancha rosa carmim 621 na base do estandarte é a cor básica da flor de g19b-94, amarelo limão 4 a de g127-97 e amarelo mimosa 602/2, a de g6-95.

Cor secundária da flor: duas linhagens possuem cor secundária da flor amarela cromo 605/1 com estrias rosa camélia 622/1: g124-95 e g167-97; seis, amarela mimosa 602: g6-95, g27-94, g58-95, g146-97, g154-95 e g184-97; g17c-94 tem a cor secundária da flor amarela mimosa 602/1 e Anão, g3-94 e g29b-94, amarela mimosa 602/2; g47-94 e g101-97, amarela mimosa 602 com estrias púrpura beterraba 830/2, g66-95 com estrias rosa camélia 622/1, g127-97 com estrias rosa claret. Fava Larga possui plantas cuja cor secundária da flor é amarela primavera 601/1 com estrias rosa carmim 621 e plantas com flores de cor secundária vermelha rubi $827 / 1$ com estrias vermelho castanho 1030. O mesmo acontece com Caqui (amarela primavera 601/1 com estrias rosa carmim 621 e vermelho rubi 827/1 com estrias vermelho castanho 1030. Este último tipoé idêntico ao de g19b-94. Finalmente, rosa magenta o27/1 é a cor secundária das flores de g18-95).

Padrão das estrias: o padrão das estrias de g10197 é denso; de g66-95 e g167-97, esparso; de Fava Larga, g19b-94, g47-94, e g124-95, médio. Caqui apresenta padrões uniforme e esparso, dependendo das cores das flores. Todas as demais apresentam padrão uniforme.

Padrão de florescimento: o padrão de florescimento de Anão, g6-95, g17c-94, g18-95, g2794, g47-94, g58-95, g66-95 e g127-97 é determinado. Das demais linhagens, indeterminado.

Cor da vagem verde: as linhagens têm as seguintes cores de vagens verdes: caqui, marrom e verde clara, em plantas diferentes; g66-95, púrpura escura com estrias verdes; g6-95, g17c-94, g27-94 e g146-97, verde: g3-94, g58-95 e g184-97, verde clara; g29b-94, verde muito clara; g19b-94, verde com estrias púrpuras claras; g47-94 e g101-97, verde com manchas violetas na linha de sutura e entre os grãos; g124-95 e g154-95, verde com estrias violetas escuras; g167-97, verde com estrias violetas escuras; g18-95, verde com manchas violetas escuras; Anão, verde escura e g127-97, verde escura com estrias violetas escuras.

Tabela 3 - Caracterização das vagens de linhagens puras selecionadas de guandu

Table 3 - Pod color and shape of pigeon-pea pure lines

\begin{tabular}{|c|c|c|c|}
\hline $\begin{array}{l}\text { Linhagem } \\
\text { Line }\end{array}$ & $\begin{array}{l}\text { Cor das vagens verdes } \\
\text { Pod shape }\end{array}$ & $\begin{array}{l}\text { Immature pode color } \\
\text { Cor das vagens maduras }\end{array}$ & $\begin{array}{l}\text { Forma das vagens } \\
\text { Mature pod color }\end{array}$ \\
\hline g3-94 & verde clara & achatada & palha \\
\hline g6-95 & verde & cilíndrica & $\begin{array}{l}\text { palha com manchas escuras junto à linha } \\
\text { de sutura e pequenas manchas violeta }\end{array}$ \\
\hline g17c-94 & verde & cilíndrica & palha \\
\hline g18-95 & verde com manchas violetas escuras & achatada & marrom claro \\
\hline g19b-94 & verde com estrias púrpuras claras & achatada & palha com estrias violeta \\
\hline g27-94 & verde & achatada & palha \\
\hline g29b-94 & verde muito clara & achatada & $\begin{array}{l}\text { palha com manchas escuras junto à linha } \\
\text { de sutura e pequenas manchas violeta }\end{array}$ \\
\hline g47-94 & $\begin{array}{l}\text { verde com manchas violetas na linha } \\
\text { de sutura e entre os grãos }\end{array}$ & achatada & $\begin{array}{l}\text { palha com manchas escuras } \\
\text { na linha de sutura e entre os grãos }\end{array}$ \\
\hline g58-95 & verde clara & cilíndrica & marrom claro \\
\hline g66-95 & púrpura escura com estrias verdes & achatada & palha com estrias púrpura \\
\hline g101-97 & $\begin{array}{l}\text { verde com estrias violetas escuras } \\
\text { na linha de sutura e entre os grãos }\end{array}$ & achatada & palha com estrias marrom violeta \\
\hline g124-95 & verde com estrias violetas escuras & achatada & marrom com estrias violeta \\
\hline g127-97 & verde escura com estrias violetas escuras & cilíndrica & palha com estrias violeta escuro \\
\hline g146-97 & verde & achatada & palha ocre \\
\hline g154-95 & verde com estrias violetas escuras & achatada & palha com estrias violeta \\
\hline g167-97 & verde com estrias violetas escuras & achatada & marrom com estrias violeta \\
\hline g184-97 & verde clara & achatada & palha \\
\hline Anão & verde escura & cilíndrica & palha \\
\hline Caqui & marrom e verde clara & achatada & violeta escuro (1) e palha (2) \\
\hline Fava Larga & verde clara e púrpura com manchas verdes & achatada & palha \\
\hline
\end{tabular}




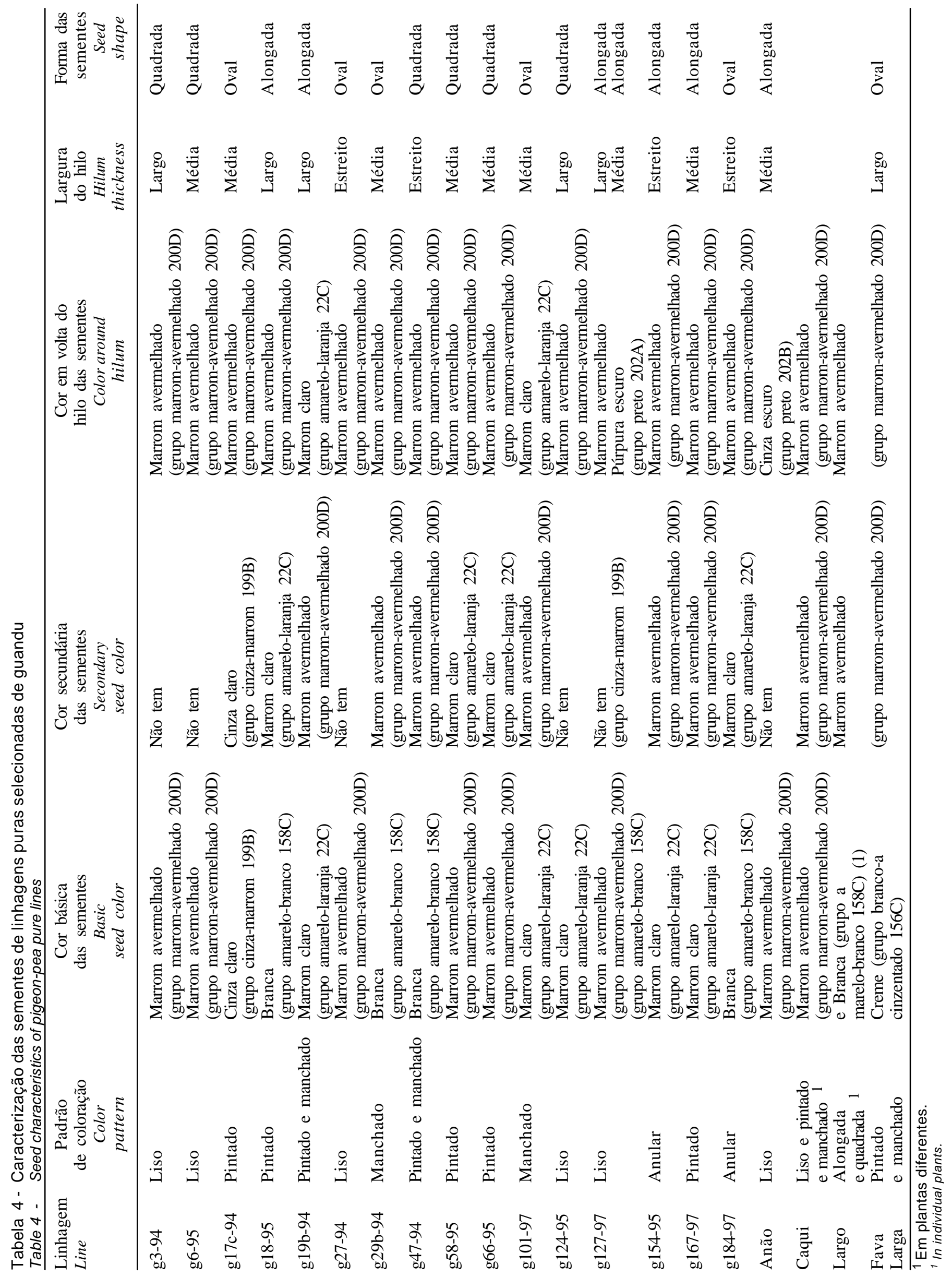


Forma da vagem: Anão, g6-95, g17c-94, g58-95 e g127-97 possuem vagens cilíndricas. As demais, achatadas.

Pilosidade da vagem: Todas os genótipos apresentam vagens pubescentes, embora em menor intensidade nas vagens de Anão e g66-95.

Cor da vagem madura: as vagens maduras de g18-95 e g58-95 são vagens marrom claro; g124-95 e g167-97, marrom com estrias violeta; Anão, Fava Larga, g3-94, g17c-94, g27-94, g184-97 e Caqui, palha, mas Caqui apresenta também vagens violetas escuras; g146-97, palha ocre; g101-97, g66-95, g15495, g19b-94 e g127-97 palha com estrias, respectivamente marrom violeta, púrpura, violeta, violeta e violeta escura; g47-94, g6-95 e g29b-94 ainda palha, porém com manchas escuras na linha de sutura e entre os grãos, para a primeira e na linha de sutura e com pequenas manchas violetas para as duas últimas.

Padrão de coloração das sementes: o padrão de coloração de sementes de g184-97, g146-97 e g15495 é anular; o de Anão, g3-94, g6-95, g27-94, g12495 e g127-97, liso; g17c-94, g18-95, g58-95 e g66-95 apresentam padrão pintado; g29b-94 e g101-97, manchado, enquanto Fava Larga, g19b-94, g47-94 e g167-97 apresentam o padrão pintado e manchado em todas as sementes. Caqui apresenta sementes com padrão liso e sementes com padrão pintado e manchado.

Cor básica das sementes; a de g18-95, g29b-94, g47-94, g146-97 e g184-97 é branca (grupo amarelobranco 158C); de g17c-94 é cinza claro (grupo cinzamarrom 199B) e de Fava Larga, creme (grupo branco-acinzentado 156C). Anão, g3-94, g6-95, g27-94, g58-95, g66-95 e g127-97 possuem sementes com a cor básica marrom avermelhada (grupo marromavermelhado 200D), assim como Caqui, que também possui sementes brancas (grupo amarelo-branco 158C). Finalmente, g19b-94, g101-97, g124-95, g15495 e g167-97 têm sementes com a cor básica marrom clara (grupo amarelo-laranja 22C).

Cor secundária das sementes: a cor secundária das sementes de g17c-94 e g146-97 é cinza claro (grupo cinza-marrom 199B); a de Fava Larga, g19b94, g29b-94, g47-94, g101-97, g154-95, g167-97 e Caqui (sementes de cor básica branca), marrom avermelhada (grupo marrom-avermelhado 200D); g18-95, g58-95, g66-95 e g184-97, possuem sementes com cor secundária marrom clara (grupo amarelolaranja 22C). As demais não têm cor secundária.

Cor em volta do hilo das sementes: a maioria dos genótipos apresenta a cor em volta do hilo marrom avermelhada (grupo marrom-avermelhado 200D). Anão possui a cor cinza escuro (grupo preto 202B), g19b-94 e g101-97 marrom claro (grupo amarelolaranja 22C) e g 146-97, púrpura escura (grupo preto 202A).

Largura do hilo: o hilo de g27-94, g47-94, g154-95 e g184-97 é estreito. Anão, g6-95, g17c-94, g29b-94, g58-95, g66-95, g101-97, g146-97 e g167-97, têm o hilo de largura média e os demais genótipos, hilos largos.

Forma das sementes: Anão, Caqui, g18-95, g19b94, g127-97, g146-97, g154-95 e g167-97 possuem sementes alongadas, sendo que Caqui também possui sementes quadradas. Fava Larga, g17c-94, g27-94, g29b-94, g101-97 e g184-97 possuem sementes ovais e as demais linhagens, sementes quadradas.

$\mathrm{Na}$ Tabela 5 pode-se observar as características do ciclo vegetativo do material avaliado. A linhagem destacadamente de florescimento mais precoce foi g58-95, cujo florescimento iniciou-se 66 dias antes do de g146-97, a mais tardia. Em ordem decrescente de precocidade estão: Anão, g17c-94, g18-95, g66-95, g6-95, g47-94, g29b-94, g127-97, Caqui, g167-97, g154-95, g184-97, g124-95, g27-94, g19b-94, Fava larga, g3-94 e g101-97. Para as características 50\% plantas em florescimento, $100 \%$ plantas em florescimento, aparecimento das primeiras vagens e $75 \%$ de vagens maduras, a ordem de precocidade foi muito semelhante à do início do florescimento. $\mathrm{O}$ período médio de florescimento foi de quatorze dias, sendo que Fava Larga apresentou florescimento muito uniforme, pois seu período de florescimento durou apenas cinco dias ao contrário de Anão, com 23 dias. Em ordem decrescente de uniformidade pode-se listar g27-94, g19b-94, g3-94, g146-97, Caqui, g29b-94, g10197, g184-97, g47-94, g66-95, g127-97, g167-97, g12495, g6-95, g17c-94, g18-95, g154-95, e g58-95.

As características utilizadas revelaram-se adequadas para a correta identificação das linhagens. A maior parte das linhagens poderia ser identificada praticamente apenas pelas características de suas sementes. Assim sementes de cor básica cinza claro (grupo cinza-marrom 199B) são de g17c-94. De cor básica branca (grupo amarelo-branco 158C) e secundária cinza claro (grupo cinza-marrom 199B), são devg146-97. Sementes de cor marrom claro (grupo amarelo-laranja 22C) pertencem à linhagem g124-95. Sementes de cor básica branca, (grupo amarelobranco 158C) e secundária marrom avermelhado (grupo marrom-avermelhado 200D), ovais são da 
Tabela 5 - Ciclo vegetativo de dezessete linhagens puras de guandu e três cultivares comerciais Table 5 - Life cicle of seventeen pure pigeon-pea lines and three commercial cultivars

\begin{tabular}{|c|c|c|c|c|c|c|}
\hline \multirow[t]{2}{*}{$\begin{array}{l}\text { Linhagem } \\
\text { Line }\end{array}$} & \multicolumn{6}{|c|}{$\begin{array}{l}\text { Dias da emergência ao (à) } \\
\text { Days from plant emergence to }\end{array}$} \\
\hline & $\begin{array}{l}\text { Início do } \\
\text { florescimento } \\
\text { Flowering } \\
\text { begginning }\end{array}$ & $\begin{array}{l}50 \% \text { plantas } \\
\text { em florescimento } \\
50 \% \text { of plants } \\
\text { flowering }\end{array}$ & $\begin{array}{l}100 \% \text { plantas em } \\
\text { florescimento } \\
100 \% \text { of plants } \\
\text { flowering }\end{array}$ & $\begin{array}{c}\text { Aparecimento } \\
\text { primeiras vagens } \\
\text { First pod appearance }\end{array}$ & $\begin{array}{l}75 \% \text { de vagens } \\
\text { maduras } \\
75 \% \text { ripe pod }\end{array}$ & $\begin{array}{c}\text { Período } \\
\text { de } \\
\text { florescimento } \\
\text { Flowering period }\end{array}$ \\
\hline Anão & 76 & 96 & 99 & 90 & 139 & 23 \\
\hline Caqui & 111 & 118 & 121 & 125 & 191 & 10 \\
\hline Fava larga & 127 & 129 & 132 & 134 & 215 & 5 \\
\hline g3-94 & 130 & 137 & 139 & 144 & 203 & 9 \\
\hline g6-95 & 93 & 109 & 111 & 113 & 165 & 18 \\
\hline g17c-94 & 85 & 100 & 103 & 105 & 141 & 18 \\
\hline g18-95 & 90 & 107 & 109 & 107 & 149 & 19 \\
\hline g19b-94 & 123 & 127 & 130 & 132 & 203 & 7 \\
\hline g27-94 & 119 & 122 & 125 & 127 & 184 & 6 \\
\hline g29b-94 & 106 & 116 & 118 & 121 & 177 & 12 \\
\hline g47-94 & 93 & 105 & 108 & 111 & 160 & 15 \\
\hline g58-95 & 69 & 79 & 90 & 90 & 127 & 21 \\
\hline g66-95 & 92 & 97 & 108 & 113 & 173 & 16 \\
\hline g101-97 & 132 & 141 & 144 & 144 & 217 & 12 \\
\hline g124-95 & 115 & 127 & 132 & 134 & 212 & 17 \\
\hline g127-97 & 109 & 123 & 125 & 127 & 203 & 16 \\
\hline g146-97 & 135 & 141 & 144 & 154 & 212 & 9 \\
\hline g154-95 & 113 & 129 & 132 & 131 & 205 & 19 \\
\hline g167-97 & 111 & 125 & 127 & 130 & 191 & 16 \\
\hline g184-97 & 114 & 123 & 127 & 130 & 206 & 13 \\
\hline $\begin{array}{l}\text { Média } \\
\text { Mean }\end{array}$ & 107 & 118 & 121 & 123 & 184 & 14 \\
\hline
\end{tabular}

linhagem g29b-94 e quadradas, de g47-94. Quando com cor secundária marrom claro (grupo amarelolaranja 22C) e alongada, pertencem à g18-95, e quando ovais, à g184-97. Sementes marrom avermelhado (grupo marrom-avermelhado 200D), sem cor secundária, alongadas, identificam g127-97 e ovais, g27-94. Sementes de cor básica marrom claro (grupo amarelo-laranja 22C), cor secundária marrom avermelhado (grupo marrom-avermelhado 200D), alongadas, com padrão de coloração anular, são de g154-95, mas quando ovais com padrão manchado são de g101-97. Sementes marrom avermelhado (grupo marrom-avermelhado 200D), sem cor secundária, quadradas e lisas, com a cor em volta do hilo marrom avermelhado (grupo marromavermelhado 200D) e hilo largo, pertencem à linhagem g3-94, mas, quando têm o hilo de largura média, pertencem à g6-95. Sementes de cor básica marrom claro (grupo amarelo-laranja 22C), cor secundária, marrom avermelhado (grupo marrom-avermelhado 200D, alongadas, com padrão de coloração pintado e manchado, de cor em volta do hilo marrom claro (grupo amarelo-laranja 22C) e hilo largo, são de g19b-94 e com hilo de largura média, de g167-97. Apenas duas linhagens, g58-95 e g66-95 precisariam de critérios adicionais para identificação, pois possuem sementes de cor primária marrom avermelhado (grupo marrom-avermelhado 200D), de cor secundária marrom claro (grupo amarelo-laranja 22C), quadradas, com padrão de coloração pintado, cor em volta do hilo marrom avermelhado (grupo marrom-avermelhado 200D) e largura do hilo média. As vagens verdes de g58-95 são de coloração verde clara, enquanto as de g66-95 são púrpura escura com estrias verdes.

Com grandes coleções, provavelmente número maior de descritores necessitasse ser usado, porém os resultados aqui obtidos sugerem ser possível alguma simplificação em relação ao proposto por IBPGR e ICRISAT (1993), o que seria conveniente, principalmente na descrição das cores do caule, flores e sementes, pois manuais de cores são de difícil obtenção e pouco práticos para utilização no campo. 


\section{Conclusões}

As dezessete linhagens descritas no presente trabalho apresentam características distintas e são facilmente identificáveis por suas características morfológicas.

Os descritores utilizados revelaram-se suficientes para caracterizar as dezessete linhagens.

A descrição de cores no caule, flores, sementes ou vagens constituiu-se no maior problema face à não disponibilidade de sistema de padrões de cores de fácil utilização e internacionalmente aceitável.

\section{Literatura Citada}

BRITISH COLOUR COUNCIL. Horticultural colour.London: The Royal Horticultural Society, 1938. 2v.

COLOMBO, C.A. Estudo da variabilidade fenotípica do feijão guandu Cajanus cajan (L.) Millsp. Piracicaba: Escola Superior de Agricultura "Luiz de Queiroz”, 1989. 131p. Dissertação (Mestrado em Zootecnia) - Escola Superior de Agricultura "Luiz de Queiroz", 1989.

GODOY, R.; BATISTA, L.A.R.; NEGREIROS, G.F. Avaliação agronômica e seleção de germoplasma de guandu forrageiro (Cajanus cajan (L.) Millsp). Revista Brasileira de Zootecnia, v.23, n.5, p.742-749, 1994.

GODOY, R.; BATISTA, L.A.R.; NEGREIROS, G.F. Avaliação agronômica e seleção de germoplasma de guandu forrageiro (Cajanus cajan (L.) Millsp proveniente da Índia. Revista Brasileira de Zootecnia, v.26, n.3, p.447453, 1997.
INTERNATIONAL BOARD FOR PLANT GENETIC RESOURCES A INTERNATIONAL CROP RESEARCH INSTITUTE FOR THE SEMI ARID TROPICS. Descriptors for pigeon-pea(Cajanus cajan(L.) Millsp.) Rome: IBPGR; Patancheru, Índia: ICRISAT: 1993. 31p.

WERNER, J.L. O potencial do guandu Cajanus cajan (L.) Millsp) como planta forrageira. Zootecnia, v.17, n.2, p.73100, 1979.

WUTKE, E.B. Caracterização fenológica e avaliação agronômica de genótipos de guandu (Cajanus cajan (L.) Millsp. Piracicaba: Escola Superior de Agricultura "Luiz de Queiroz", 1987. 164p. Dissertação (Mestrado em Fitotecnia) - Escola Superior de Agricultura "Luiz de Queiroz", 1987.

Recebido em: $14 / 05 / 02$

Aceito em: 23/10/02 